\title{
Short-term evidence on wellbeing of rural Ethiopian households during the COVID-19 pandemic
}

\author{
Harold Alderman, Daniel O. Gilligan, Melissa Hidrobo, Jessica Leight, Alemayehu \\ Seyoum Taffesse, Heleene Tambet
}

\section{Introduction}

In Ethiopia, as in much of sub-Saharan Africa, the first known case of coronavirus arrived in mid-March (on March 13, 2020), weeks after the pandemic had spread rapidly in parts of Europe and the United States. The government swiftly imposed restrictions to slow the spread of the virus, closing schools (on March 16, 2020), limiting travel and encouraging people to remain at home. Such restrictions were needed to keep the pandemic from overwhelming a healthcare system with limited capacity to respond to an infectious disease outbreak. Only limited information is available about the effect of these restrictions on economic activity, food security and livelihoods in Ethiopia. A survey of residents of Addis Ababa conducted in May 2020 found that more than half of households reported lower-than-expected incomes and more than one third were extremely stressed about the situation [1]. These results further showed that poorer households were more severely affected, although the food security situation in Addis, while declining, was not yet dire.

Far less is known about the effects of COVID-19 on livelihoods and wellbeing of rural Ethiopian households and particularly among the poor. ${ }^{1}$ Given that the poorest households in rural Ethiopia are heavily dependent on subsistence production and often only minimally integrated into long-distance supply chains, major commercial sectors, and systems of international migration and remittances, it is plausible

\footnotetext{
${ }^{1}$ A survey conducted by the World Bank building on the national longitudinal Ethiopia Socioeconomic Survey in June 2020 included both urban and rural households across Ethiopia; the sample was constructed to be representative of access to a working phone, and thus included approximately one third rural households. This survey reports meaningful income loss for rural households, but also analyzes a population that is substantially less poor than that analyzed here: only $10 \%$ of rural households report receipt of any government assistance, while all households in the sample analyzed here are poor enough to be eligible for PSNP transfers. Perhaps reflecting this less poor sample, the first round of the World Bank survey also shows limited use of coping strategies thus far, with a majority of even rural households reporting no meaningful changes in coping mechanisms.
} 
to expect that these households may be partially buffered from the effect of COVID-related shocks, at least in the short-term. However, this hypothesis remains largely unexplored.

We present results of a phone survey, conducted in early June 2020, of more than 1,100 rural households who are beneficiaries of the fourth phase of Ethiopia's Productive Safety Net Program (PSNP4) and who also participate in the USAID-funded Strengthening PSNP4 Institutions and Resilience (SPIR) project, implemented by World Vision, CARE and ORDA in North Wollo and Wag Himra zones in Amhara, and primarily in East and West Hararghe zones in Oromia. The phone survey respondents are adult males from sample households in IFPRI's experimental impact evaluation of SPIR who provided a phone number during the 2019 midline survey. This is a subsample of the broader SPIR evaluation sample; $33 \%$ of households provided a phone number and thus are eligible for inclusion in the phone survey, while $67 \%$ of households did not provide a phone number and thus cannot be included in the phone survey. Available evidence suggests that households who provided a phone number are characterized by higher socioeconomic status vis-à-vis other SPIR households in the study sample who did not provide a phone number. (However, all households in the phone survey are SPIR beneficiaries and thus are relatively poor in the broader context of rural Ethiopia.)

We report evidence from this survey on coronavirus awareness, protective measures taken and coping strategies; changes in livelihoods and food security; assistance received; and experience and expectations with desert locusts, another significant shock affecting some of the study areas. We consider implications of the patterns of effects for response to the pandemic.

\section{Survey description}

The COVID-19 phone survey was conducted from June 1-14, 2020 in conjunction with the research and survey firm Laterite. Enumerators worked from their homes, calling respondents and recording survey responses on tablet computers. Enumerators interviewed 1,188 households out of a target sample of 1,326 households in the SPIR midline survey known to have phones. This represents a response rate of $89.6 \%$, far higher than many other COVID-19 phone surveys. The survey enumeration and supervision team contacted local leaders and guides who accompanied the team during the SPIR midline survey in July-September 2019, for assistance in contacting those who provided phone numbers but could not be reached. This approach made it possible to contact and interview such a high share of the target sample. Interviews were roughly 25 minutes in length on average. Respondents were provided a mobile phone credit of 100 Ethiopian birr.

\section{Coronavirus awareness, responses and reported effects}

Virtually all households in the survey are aware of coronavirus. The vast majority ( $>80 \%)$ report widespread use of protective measures in the last seven days, including handwashing, social distancing, and avoiding large gatherings (Figure 1). A smaller majority (56\%) report wearing masks. Respondents in Oromia report somewhat higher adherence to social distancing measures than those in Amhara. Radio paid a key role in raising awareness about coronavirus; twice as many respondents named it as a source of information about the virus as named friends or neighbors.

Half of all respondents ( $70 \%$ in Oromia) perceive their risk of coronavirus infection is high, while nearly $15 \%$ of all respondents (20\% in Amhara) perceive they have no risk of becoming infected. Those who perceive no/low risk of infection attribute this minimal risk level to their use of protective measures and to their faith. 
Respondents report a variety of negative effects of the pandemic, including closures of schools, shops and churches/mosques; lost income or food shortages; travel restrictions and social distancing; and sickness or fear of getting sick or dying (Figure 2a). Although school closures were nearly universal in Amhara as they were in Oromia, churches and mosques in Amhara mostly remained open, while they were largely closed in Oromia. The largest negative reported impacts of coronavirus are travel restrictions, food shortages and income loss (Figure 2b). Food shortages were much more prevalent in Oromia (90\%) than in Amhara (52\%); food shortages were reported as the negative effect of coronavirus with the greatest impact on households in Oromia, whereas travel restrictions and income losses were more often listed as the worst effect of coronavirus in Amhara.

Figure 1: Protective measures used in past 7 days

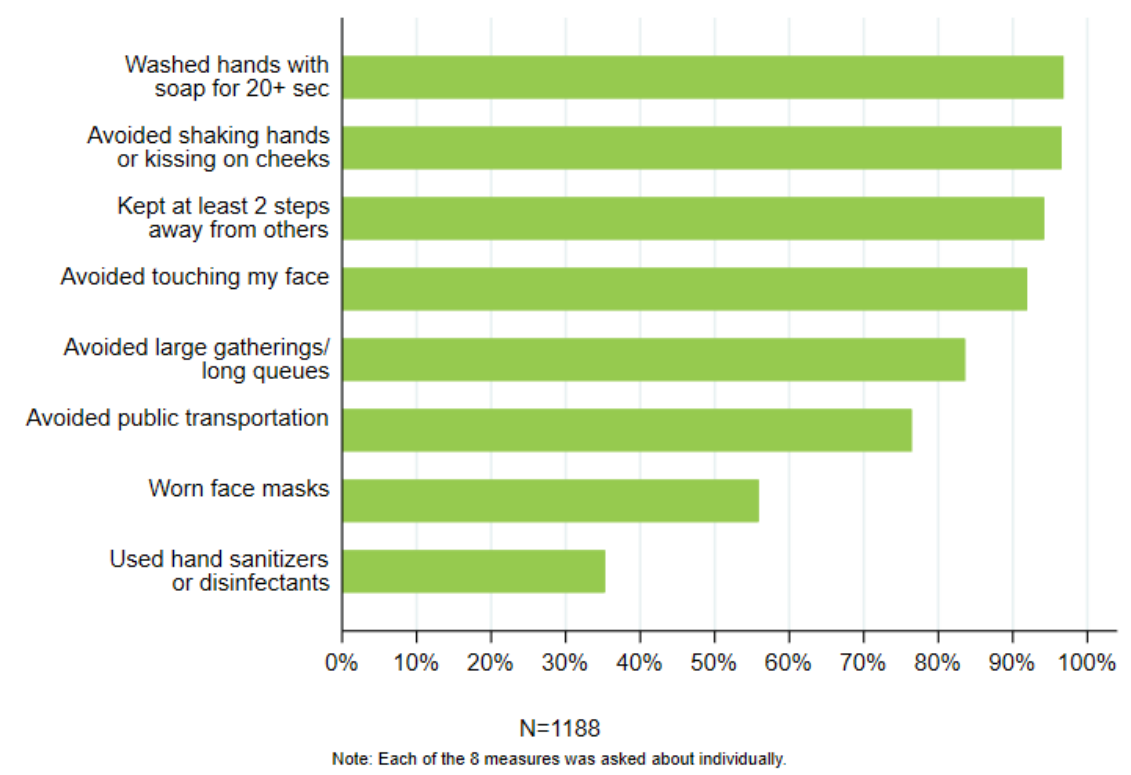

Figure 2a: Aspects on coronavirus that have had an impact on the household, by region

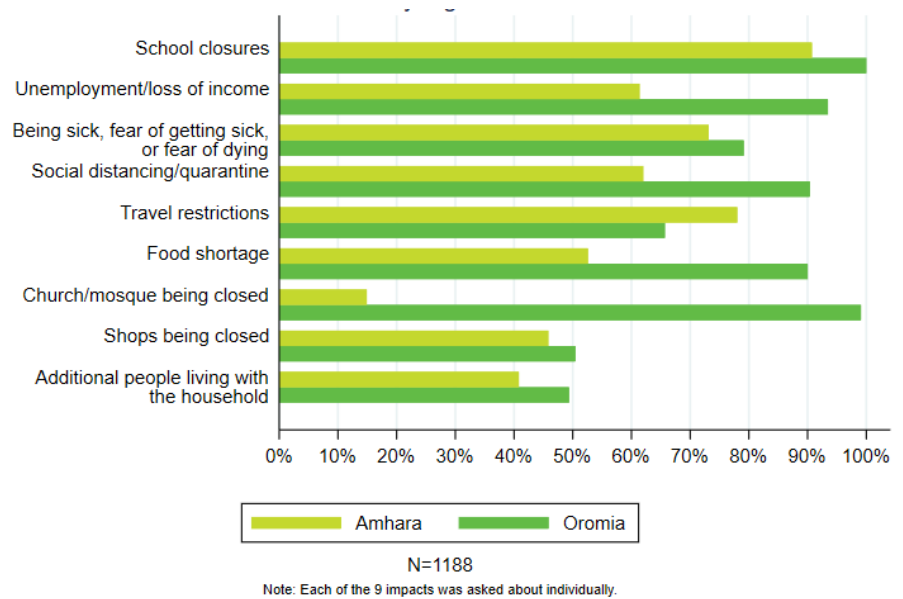

Figure 2b: Aspect of coronavirus with the greatest impact on the household, by region

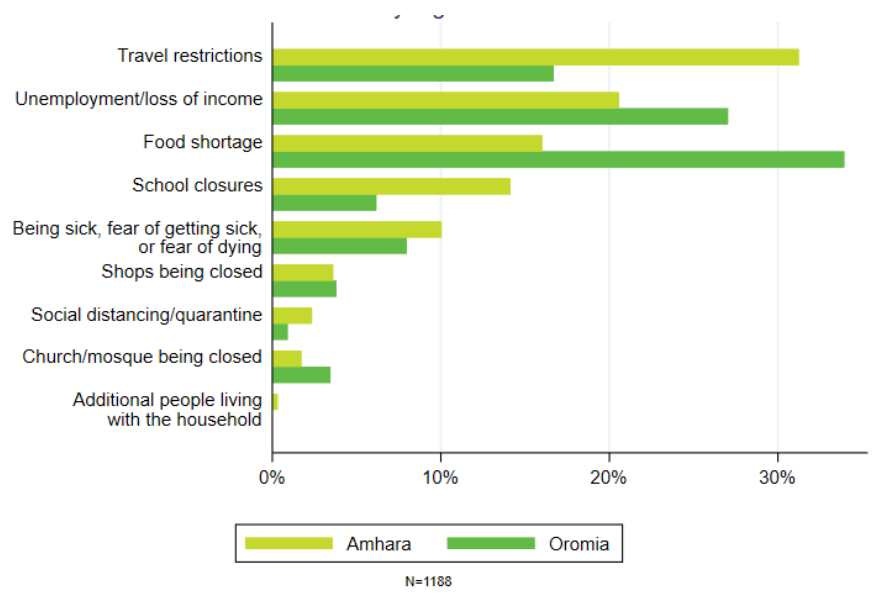




\section{Short-term changes in livelihoods}

The survey included a set of targeted questions designed to identify the effect of COVID-related shocks on respondents' livelihoods. The majority of the questions were framed to collect retrospective information about the effect of shocks since the beginning of Lent (February 24, 2020), a date that was chosen both for its salience and its proximity to the initiation of the pandemic.

As evident in Figure $3 a$, the overwhelming majority $(80 \%)$ of respondents report that they have experienced a decrease in income since this date. This pattern is broadly consistent across both Amhara and Oromia, and is also consistent for households with varying levels of reported consumption at baseline. The decrease in income is observed across all four enumerated income sources: $70 \%$ of households report a decline in income from family farming and livestock raising; $92 \%$ of households with a non-farm family business report lost income; $30 \%$ of wage earners report a total income loss from this source; and half of households receiving remittances report a decline, though this is relatively few households.

In order to manage this decline in income, households used a range of coping mechanisms. The most commonly reported mechanisms are (in order) the sale of assets, the receipt of aid from non-governmental organizations, the reduction of consumption, the identification of additional income sources, and the drawdown of savings, as shown in Figure $3 \mathrm{~b}$. These responses are also broadly similar across regions, though households in Oromia are much more likely to report the receipt of aid vis-à-vis households in Amhara; more than $60 \%$ of households on Oromia report drawing on aid, while less than $10 \%$ of households in Amhara do so.

Figure 3a: Change in household's income since February 24, 2020

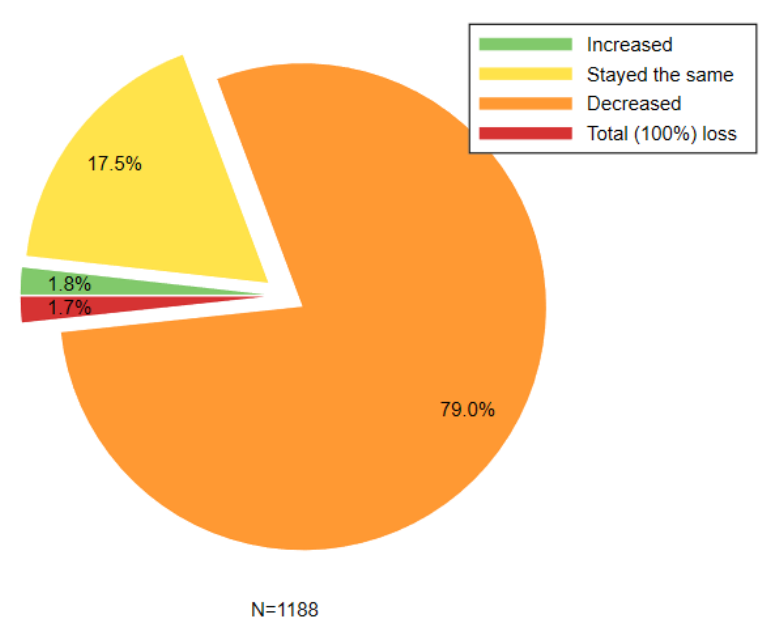

Figure 3b: Coping mechanisms used to deal with the income loss

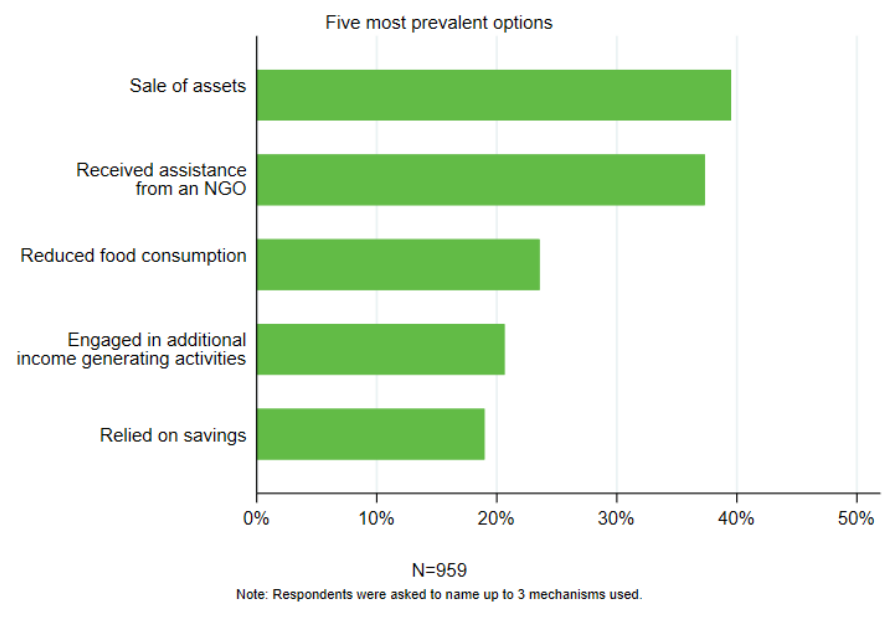

When probed further about the evolution of livestock assets, a primary form of asset holdings for rural households, $45 \%$ of households report a decrease in asset stocks. However, only $25 \%$ of those households reporting a decrease in livestock state that this reflects a sale linked to emergency income needs. Other households reporting a decrease in livestock report either sales for normal income needs, or nat- 
ural deaths. In addition, when probed further about cropping activities during the most recent Belg season, ${ }^{2}$ virtually all households that grew crops report that they have been able to perform normal crop cultivation activities (e.g., purchase of inputs, planting, etc.) despite the pandemic. Reporting from the SPIR project team showed that several woredas experienced crop losses due to low rainfall and pest infestations from fall armyworm and, in some locations, desert locusts. These shocks to crop income as well as losses from livestock raising could explain the high share of households reporting crop and livestock income losses despite being able to perform normal farming activity.

In the context of potentially substantial shocks to their livelihoods, respondents also report a high level of stress (about $60 \%$ of respondents report the maximum stress level out of ten), and a low level of selfreported well-being. Self-reported stress is dramatically higher in Oromia, where more than $80 \%$ of respondents report the maximum stress level, compared to Amhara, where around $35 \%$ report this level of stress (shown in Figure 4).

Figure 4: Self-reported stress levels, by region (1 = not stressed at all, 10 = extremely stressed)

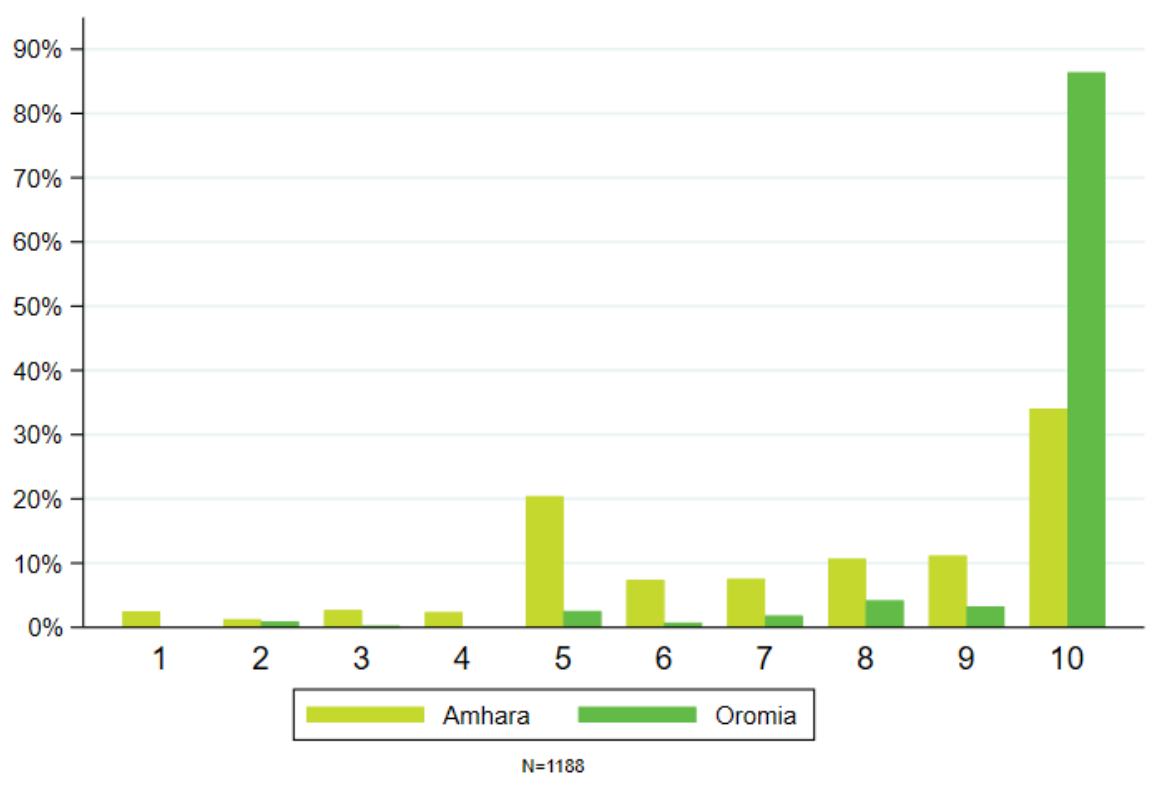

\section{Short-term changes in food insecurity}

Food insecurity was assessed using three different measures: 1) how long a household can meet its food security needs with the resources it has on hand; 2) the Food Insecurity Experience Scale (FIES) ${ }^{3}$; and 3) a binary indicator for whether children have decreased their consumption of dairy and eggs since COVID-19. There are large differences across regions in food insecurity, with Oromia displaying higher rates of food insecurity across all three measures. Figure 5 a reveals that around $30 \%$ of households in Oromia compared to $10 \%$ in Amhara would be able to meet its food need for less than a week with the resources it has on hand, indicating high levels of food vulnerability especially in Oromia. Consistent with

\footnotetext{
${ }^{2}$ The Belg season is the smaller of the two seasons in Ethiopia. Sixty percent of respondents reported that they grew crops during the current Belg season.

${ }^{3}$ Raw scores are used to create the food insecurity categories; the thresholds for the classification are assigned by the authors.
} 
this around $50 \%$ of households in Oromia are severely food insecure compared to around $12 \%$ in Amhara according to the FIES (Figure $5 b$ ).

Figure 5a: How long could household meet its food needs with current resources, by region

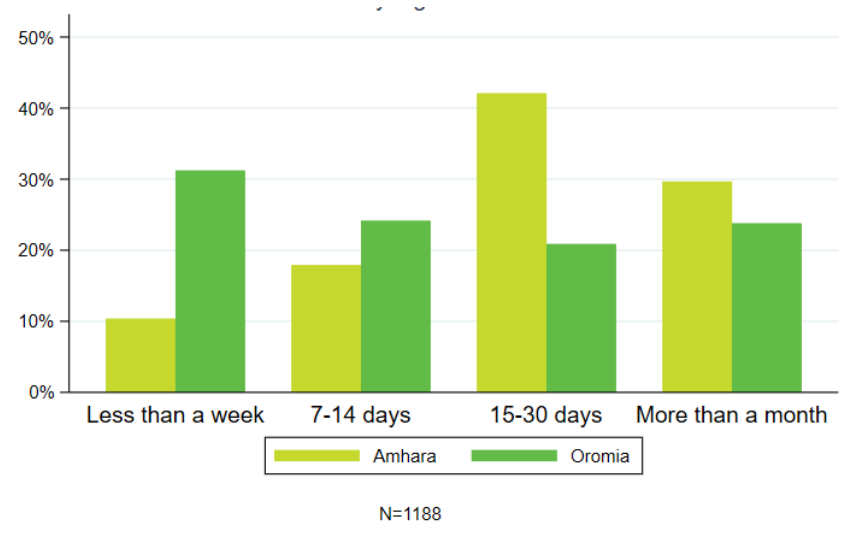

Figure 5b: Food Insecurity Experience Scale*, by region

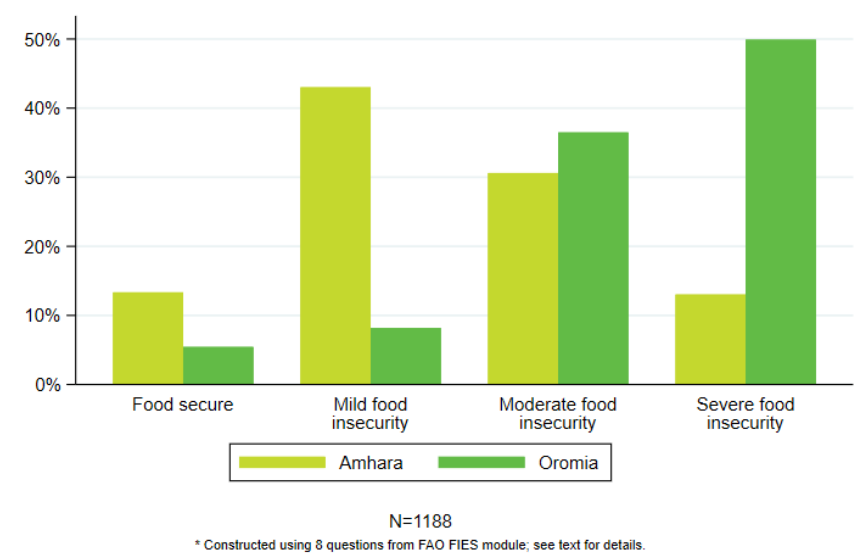

The humanitarian response to major economic and climate shocks in Ethiopia are governed by a twiceannual humanitarian food insecurity hotspot classification at the woreda level, where the highest risk woredas are classified as Priority 1 and the lowest risk woredas are classified as Priority 3 . We examined the level of food insecurity during the pandemic as well as the greatest negative effect of the pandemic by hotspot classification (see Table 1). As expected, the share of households experiencing severe food insecurity according to the FIES is highest in Priority 1 areas. However, the regional differences are striking: households in Priority 1 woredas in Oromia are more than twice as likely to be severely food insecure than Priority 1 households in Amhara, and Priority 2 woredas in Oromia also have more than double the share of severely food insecure households by this measure than Priority 1 households in Amhara. Next, we report the top three largest negative impacts of COVID-19 by hotspot classification. Despite the response so far, food shortages remain the worst effect of COVID-19 in Priority 1 woredas, followed by loss of income and travel restrictions. In lower priority locations, travel restrictions are the leading concern. 
Table 1: Food insecurity and COVID-19 shocks by Woreda-level hotspot classification

\begin{tabular}{l|lc|lll}
\hline & \multicolumn{2}{|c|}{$\begin{array}{c}\text { Share of severely insecure } \\
\text { households (FIES) }\end{array}$} & \multicolumn{3}{c}{ Greatest impact of COVID-19 is... } \\
\hline $\begin{array}{l}\text { Woreda hotspot } \\
\text { classification by }\end{array}$ & Amhara & Oromia & $\begin{array}{l}\text { Unemployment/ } \\
\text { loss of income }\end{array}$ & $\begin{array}{l}\text { Food short- } \\
\text { ages }\end{array}$ & $\begin{array}{l}\text { Travel re- } \\
\text { strictions }\end{array}$ \\
\hline 1 & $22.5 \%$ & $50.6 \%$ & $24.7 \%$ & $33.0 \%$ & $18.4 \%$ \\
& 102 & 413 & 515 & 515 & 515 \\
2 & $11.1 \%$ & $47.8 \%$ & $23.2 \%$ & $17.5 \%$ & $27.6 \%$ \\
& 387 & 138 & 525 & 525 & 525 \\
3 & $11.5 \%$ & - & $20.1 \%$ & $18.2 \%$ & $34.5 \%$ \\
& 148 & & 148 & 148 & 148 \\
\hline
\end{tabular}

Source: Hotspot classification provided by the GoE National Disaster Risk Management Commission (NDRMC)/Emergency Nutrition Coordination Unit (ENCU), January 2020. Food insecurity and COVID-19 impact data are from the SPIR phone survey.

Consistent with the decreases in income due to COVID, the majority of households $(70 \%)$ report decreases in children's egg and dairy consumption since February 24, 2020 (Figure 6), with a larger proportion of households reporting decreases in Oromia compared to Amhara (around $80 \%$ in Oromia compared to around $60 \%$ in Amhara). As these foods are important components of diet diversity and were consumed in low amount even prior to the COVID-19 restricted activities, this is worrisome.

Figure 6: Changes in children's dairy and egg consumption since February 24, 2020

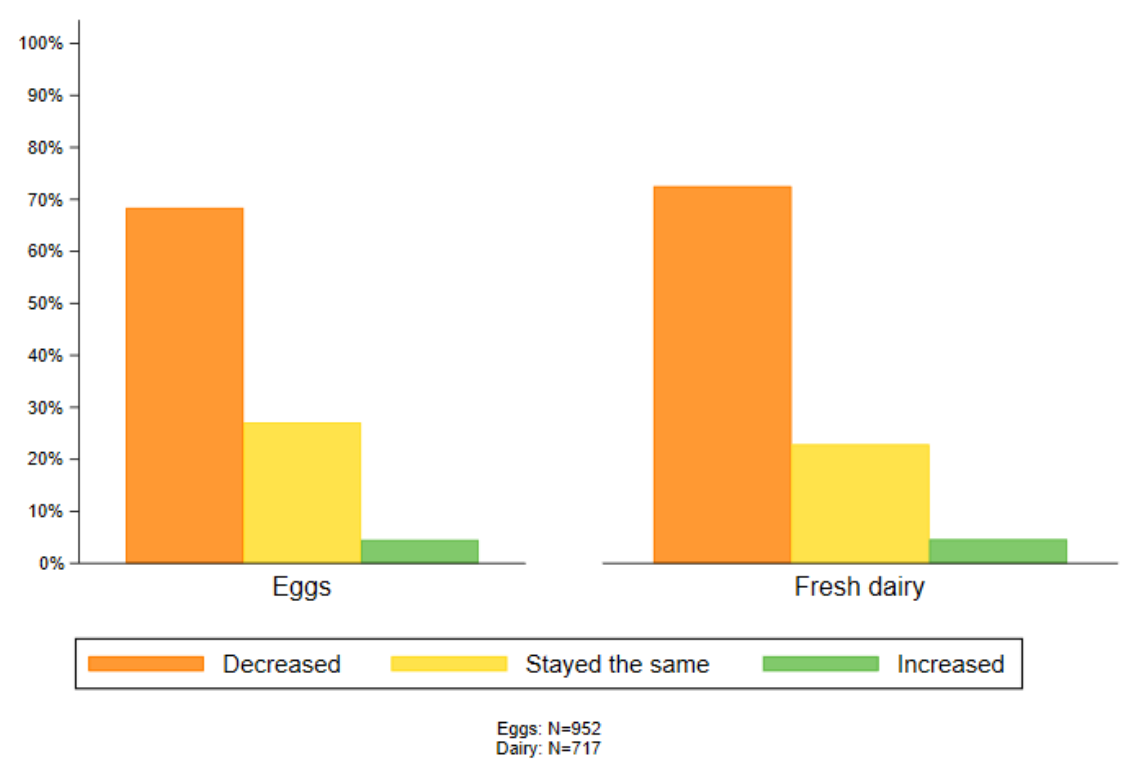

\section{Access to assistance during the pandemic}

Food and cash transfers from social protection programs like the PSNP4 are being used to respond to the virus in many countries [2] because of their ability to help maintain food security and reduce distressed sales of assets, which can have protracted negative long-term consequences. We asked respondents, 
who are all PSNP4 beneficiary households, whether they had received social assistance since the start of Lent, just before the pandemic was recognized in Ethiopia. At least two thirds of respondents report receiving food- or cash-for-work. A common recommendation is to drop work requirements and other conditions for receiving food or cash payments, in order to reduce the risk of people gathering and to allow transfer recipients time to manage their response [3]. However, in Amhara region, less than 15\% of households reported receiving assistance without work requirements, suggesting that work requirements continued to be enforced at some level in Amhara after the start of the pandemic.

\section{The double shock of COVID-19 restrictions and desert locusts}

Twenty percent of households in Oromia reported crop damage due to desert locusts in the meher season of 2020 . Similarly, $30 \%$ of the households in that region reported damage to grazing land in 2020 compared to $10 \%$ of the respondents in Amhara. Households that have incurred crop losses are far more likely to have severe food insecurity (Figure 7). However, as Oromia has the highest rates of poverty and food insecurity in general, it is difficult to separate the impact of this infestation from the other causes of food insecurity.

Figure 7: Food Insecurity Experience Scale* by experienced crop losses due to desert locust damage in 2019

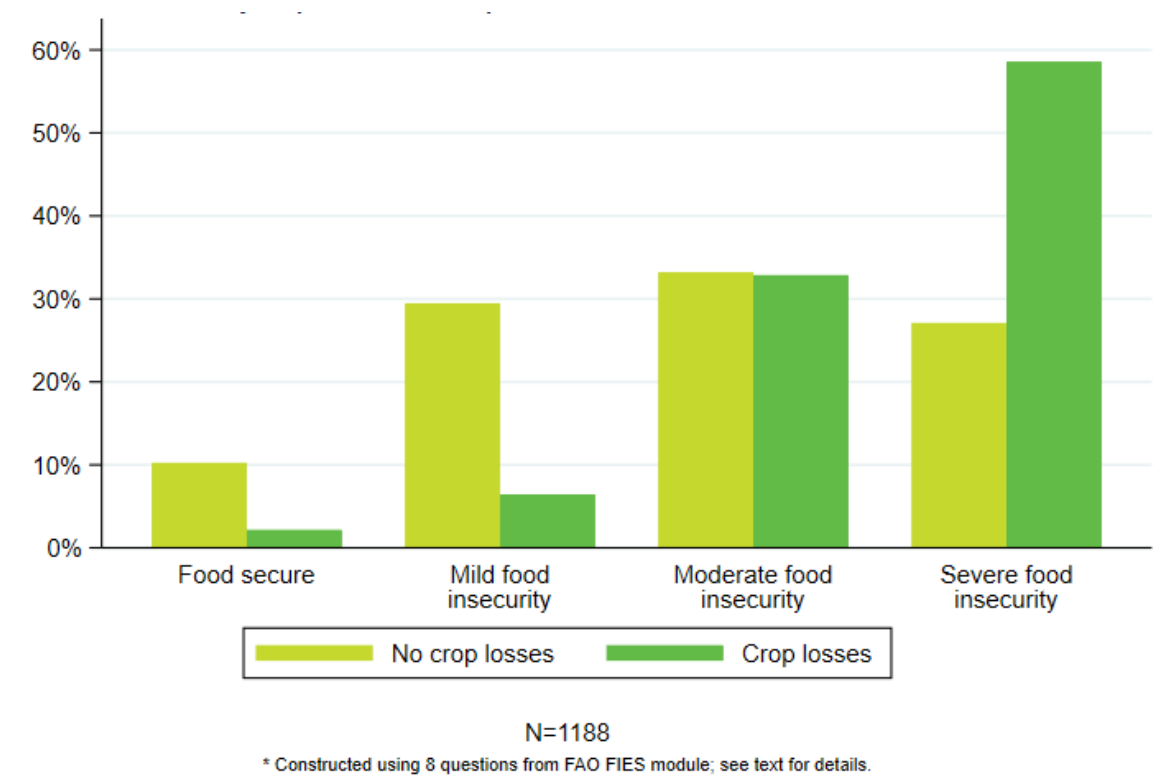

However, although the reported damage prior to the survey was largely confined to Oromia all households are aware of the risk, generally claiming they knew of the locusts from personal experience; most households are concerned about the risk over the 3 months following the survey (see Figure 8). The concern, however, does not differ by wealth. 
Figure 8: Concern about the effect of desert locusts over the next 3 months, by region

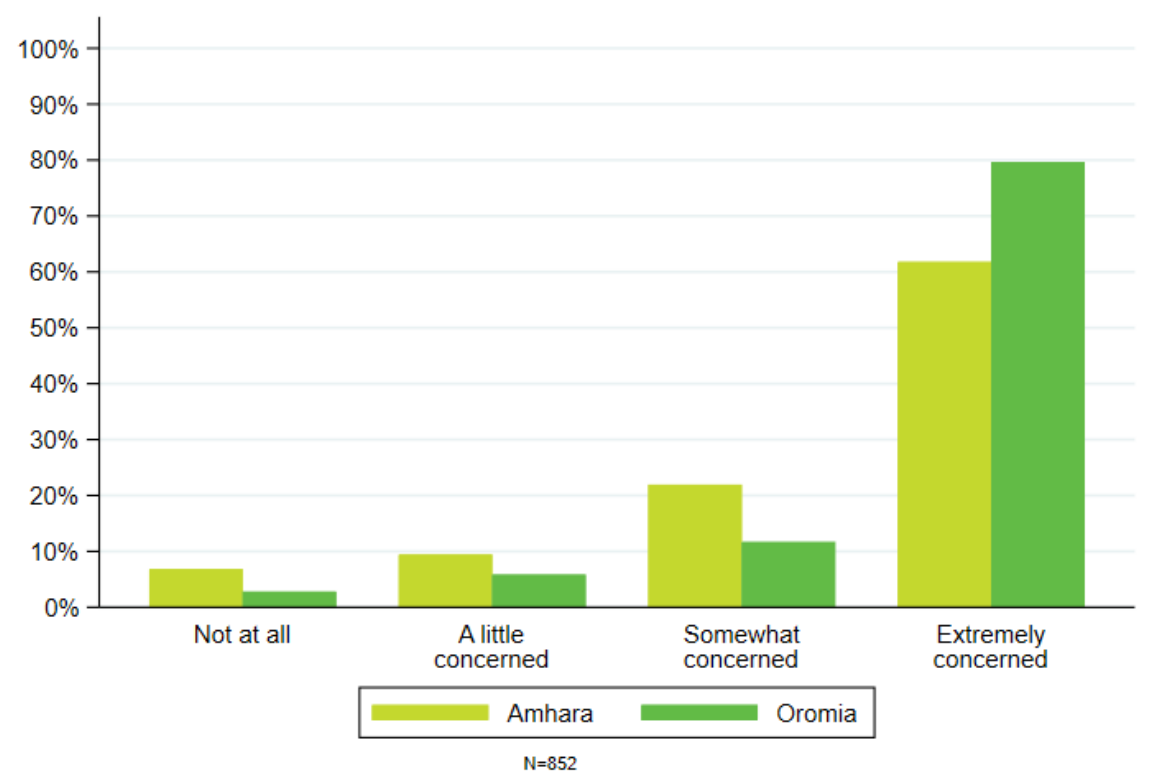

\section{Conclusions}

Evidence collected from this phone survey of 1,188 respondents nearly three months following the onset of pandemic-related restrictions in Ethiopia suggests that poor rural households are experiencing substantial shocks linked to COVID-19. Rural households report widespread use of protective measures, but nonetheless report a considerable fear of infection (particularly in Oromia) and note a range of adverse effects of pandemic-related restrictions. Reported disruption to livelihoods and increased food insecurity are also substantial, again particularly in Oromia. This combination of pandemic-related shocks, seasonal rainfall and pest shocks, and other regional factors likely all contribute to alarmingly high rates of stress in Oromia, where more than $85 \%$ of respondents say their stress is a 10 out of 10 . This suggests an urgent need for the kind of mental health services being piloted as part of the SPIR project. There is evidence, however, that respondents continue to benefit from social protection programs and other forms of non-governmental aid as they manage this shock. These results suggest that ongoing tracking of COVID-19 effects on vulnerable households will be crucial in order to facilitate the adaptation of existing social protection programs to address the multifaceted consequences of this pandemic. 


\section{ACKNOWLEDGMENTS}

We gratefully acknowledge funding for the impact evaluation from the United States Agency for International Development (USAID) under Cooperative Agreement No. AID-FFP-A-16-00008. This work was undertaken as part of the CGIAR Research Program on Policies, Institutions, and Markets (PIM) led by the International Food Policy Research Institute (IFPRI). Additional funding support for this study was also provided by PIM. Michael Mulford, Chief of Party of the SPIR project, shares intellectual credit for study research design. We also thank our partners at World Vision, CARE, and ORDA for their contributions to the study and overall support. Thanks also to the research teams at Ambo University and Hawassa University for their feedback on the study design.

\section{REFERENCES}

[1] Hirvonen, Kalle, Gashaw T. Abate, and Alan de Brauw. May 2020. Food and nutrition security in Addis Ababa, Ethiopia during COVID-19 pandemic: May 2020 report. Washington DC: International Food Policy Research Institute.

[2] Gentilini, Ugo. 2020. Weekly Social Protection Links. May 22. Accessed June 2020. https://www.ugogentilini.net/?p=920.

[3] Gilligan, Daniel. June 18, 2020. Social safety nets are crucial to the COVID-19 response. Some lessons to boost their effectiveness. https://www.ifpri.org/blog/social-safety-nets-are-crucial-covid-19-response-some-lessons-boost-their-effectiveness

This publication was produced by IFPRI in collaboration with World Vision on the SPIR Program, Cooperative Agreement Number XX, funded by the U.S. Agency for International Development.

This Learning Brief is made possible by generous support of the American people through the United States Agency for Intenational Development (USAID). The contents are the responsibility of the authors and do not necessarily reflect the views of USAID or the United States Government.

This publication has been prepared as an output of Strengthen PSNP4 Institutions and Resilience (SPIR) impact evaluation and has not been independently peer reviewed. Any opinions expressed here belong to the author(s) and are not necessarily representative of or endorsed by IFPRI.

INTERNATIONAL FOOD POLICY RESEARCH INSTITUTE

A world free of hunger and malnutrition

IFPRI is a CGIAR Research Center 